\title{
ESTUDO DA VIABILIDADE DE DISPOSIÇÃO FINAL DOS LODOS DE ETAS EM ATERROS SANITÁRIOS
}

\author{
Cristiane Silveira \\ Daniele Satie Koga \\ Emília Kiyomi Kuroda
}

RESUMO: Dentre as formas de disposição final da fração sólida do lodo de decantadores de ETAs após a desidratação está a disposição em aterros sanitários em substituição ao solo. O objetivo desse estudo foi avaliar se lodo de decantador após desidratação pode ser disposto em aterros sanitários, uma vez que os metais presentes no lodo desidratado não lixiviam causando impactos ambientais. Para isso, primeiramente foram realizados ensaios de desaguamento em leitos de drenagem e secagem com manta geotêxtil, e em seguida foram realizados para os lodos desidratados o teste de lixiviação e a classificação, de acordo com as NBRs 10.004, 10.005 e 10.006 (ABNT, 2004). Como resultados, o ensaio em colunas de lixiviação revelou que os lodos de ETAs desidratados com teor de sólidos de em média $80 \%$, podem ser dispostos como cobertura de células em aterro sanitário, uma vez que os metais presentes não foram disponibilizados quando em contato com a água. Além disso, foi possível obter a classificação dos os lodos tipos $\mathrm{A}$ e B, os quais foram classificados como resíduo Classe II A - Não inertes.

\section{INTRODUÇÃO}

A norma técnica NBR 10.004 (ABNT, 2004) classifica os lodos provenientes de sistemas de tratamento de água como resíduos sólidos, os quais devem ser tratados e dispostos dentro dos critérios nela definidos.

O tratamento de lodos de estações de tratamento de águas - ETAs, consiste basicamente numa separação sólido-líquido, via clarificação / adensamento e desidratação e tem como objetivo a redução de volume do lodo, obtenção de maior teor 
de sólidos, possibilitando a disposição adequada da fração sólida e disposição ou reutilização da água removida.

A forma mais comum de disposição final da fração sólida do lodo de ETAs após a desidratação é feita em aterros sanitários. No entanto, a presença de alguns compostos químicos, tais como íons metálicos, utilizados no processo de tratamento de água, pode constituir um obstáculo para os aterros que não aceitam materiais sólidos, tornando esta operação restrita (HOPPEN, 2004). Além disso, a codisposição de lodo de ETA pode gerar a redução da capacidade do aterro bem como intensificar a necessidade do monitoramento de água subterrânea desta região e de água de lixiviação.

Com o objetivo de proporcionar ao lodo de ETA desidratado um destino mais nobre, Rodriguez et. al. (2011) estudaram a viabilidade da substituição do solo utilizado como camada de cobertura ou de impermeabilização de fundo, pelo lodo desidratado da ETA Cafezal de Londrina - PR e traços solo-lodo. Após avaliação do comportamento mecânico do lodo desidratado bem como de traços solo-lodo e comparação com o comportamento mecânico do solo laterítico da região de Londrina, utilizado como impermeabilização de fundo e cobertura em aterro sanitário, o estudo revelou que sob esse ponto de vista, o solo pode ser substituído pelo lodo de ETA desidratado compactado ou por traços de solo-lodo.

Segundo Ferranti (2006) a concentração de metais predomina de forma sensível na fase sólida do lodo, fato este que pode fazer com que, quando expostos à umidade dos resíduos ou à precipitação, esses metais percolem oferecendo impactos ambientais.

Dentro desse contexto, o objetivo desse estudo foi avaliar se os metais presentes em dois lodos de decantadores de ETA desidratados podem percolar para a fase líquida, quando dispostos em aterros sanitários e expostos à umidade, interferindo tanto na decomposição dos resíduos, quanto causando impactos negativos ao meio ambiente. 


\section{MATERIAIS E MÉTODOS}

\subsection{Ensaios de desaguamento em leitos de drenagem / secagem com manta geotêxtil}

Foram utilizados dois lodos de decantadores, ambos coletados em ETAs localizadas na cidade de Londrina - PR. O lodo tipo A, foi proveniente da ETA Cafezal a qual utiliza o cloreto férrico como coagulante químico, e tipo $\mathrm{B}$, proveniente da ETA Tibagi, que utiliza o hidróxi-cloreto de polialumínio como coagulante químico.

Para obtenção do lodo desidratado, a técnica de desaguamento utilizada foi leito de drenagem e secagem com manta geotêxtil. As unidades de desaguamento foram construídas em escala reduzida, e compostas por um tanque de polietileno com capacidade de $30 \mathrm{~L}$, provido de uma grelha plástica para suporte da manta geotêxtil e tubulação de saída inferior para coleta da água drenada.

Os desaguamentos foram divididos em duas fases distintas e consecutivas: fase de drenagem (até extinção da lâmina líquida) e fase de secagem, com duração total entre 7 e 15 dias para completa desidratação do lodo e elevado teor de sólidos.

\subsection{Ensaio em colunas de lixiviação}

Para avaliar os efeitos de lixiviação simulando uma possível situação de precipitação em campo quando o lodo de ETA desidratado for usado como cobertura de células em aterros sanitários, foi realizado em laboratório um ensaio em colunas de lixiviação em protótipos de escala reduzida.

As colunas foram construídas usando tubos de PVC, com altura de $50 \mathrm{~cm}$ e diâmetro de $10 \mathrm{~cm}$, na base foi adaptado um CAP com fundo recortado, acrescido de uma grelha e uma manta geotêxtil (gramatura de $150 \mathrm{~g} \cdot \mathrm{m}^{-2}$ ) para suporte da camada de lodo, para coleta do líquido percolado foi adaptado um dispositivo de fundo cônico. Cada coluna foi preenchida com um tipo de lodo até uma altura de $30 \mathrm{~cm}$. 
Segundo dados do IAPAR - Instituto Agronômico do Paraná, a precipitação média anual de Londrina é de $1610 \mathrm{~mm}$, ocorrendo em média em 121 dias do ano. Baseado nesses dados e na área dos protótipos em escala reduzida utilizados nesse teste, simulou-se uma condição crítica de precipitação contínua de $3,5 \mathrm{~mL} \cdot \mathrm{min}^{-1}$ (equivalente a 50 vezes o valor da precipitação média anual de Londrina-PR), aplicadas por 3 mangueiras / protótipo, simulando uma distribuição mais uniforme no lodo por um período de 6 dias.

A simulação da precipitação foi realizada com água ultrapura simultaneamente nas colunas de lodo tipos A e B através de uma bomba peristáltica previamente regulada para a vazão definida.

As Figuras 1 e 2 mostram um esquema e a foto do ensaio em colunas de lixiviação, respectivamente.

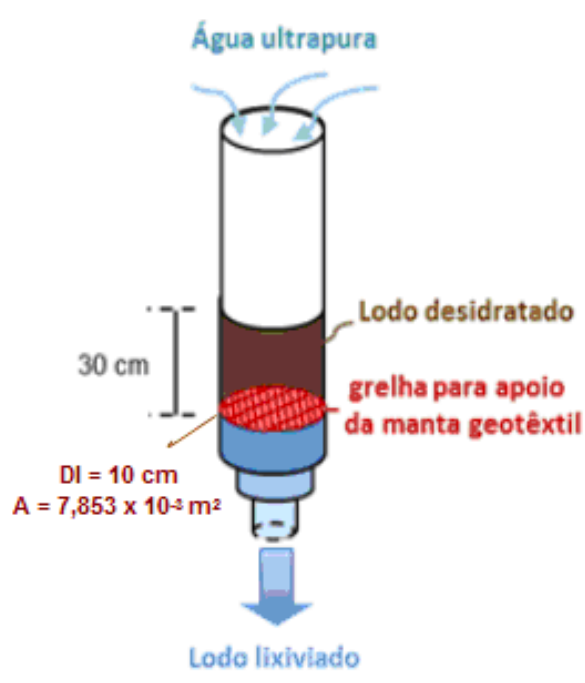

Figura 1 - Esquema do ensaio de lixiviação dos lodos tipos A e B

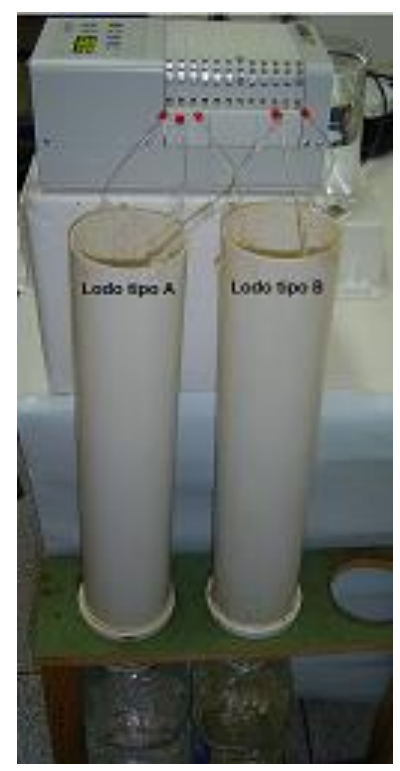

Figura 2 - Foto do ensaio de lixiviação dos lodos tipos A e B

Todo o líquido lixiviado das colunas foi coletado diariamente em recipientes de $5 \mathrm{~L}$, e reservados para posterior constituição das amostras compostas. As amostras compostas dos líquidos lixiviados foram caracterizadas quanto aos parâmetros físicos e químicos apresentados na Tabela 1, seguindo procedimentos da APHA, AWWA e WEF 
(2005) com adaptações. As análises para quantificação dos metais foram realizadas por um laboratório credenciado por prestação de serviço.

Tabela 1 - Parâmetros e métodos / equipamentos utilizados na caracterização dos líquidos drenados das colunas de lixiviação

\begin{tabular}{|c|c|}
\hline Parâmetro & Método \\
\hline Turbidez (uT) & Nefelométrico - $2130 \mathrm{~B}$ \\
\hline Cor aparente $(\mathrm{uH})$ & Espectrofotométrico $2120 \mathrm{C}$ \\
\hline $\mathrm{pH}$ & Potenciométrico - 4500 \\
\hline $\begin{array}{c}\text { Demanda Bioquímica de Oxigênio - } \mathrm{DBO}_{5 \mathrm{~d}}, 20^{\circ} \mathrm{C} \\
\left(\mathrm{mg} \cdot \mathrm{L}^{-1}\right)\end{array}$ & Teste DBO 5 dias a $20^{\circ} \mathrm{C}-5210$ \\
\hline Demanda Química de Oxigênio DQO $\left(\mathrm{mg}^{-\mathrm{L}^{-1}}\right)$ & Refluxo fechado / $5220 \mathrm{D}$ \\
\hline Série de sólidos $\left(\mathrm{mg} \mathrm{L}^{-1}\right)$ & $\begin{array}{c}\text { Sólidos secos a } 103-105^{\circ} \mathrm{C} ; \\
\text { Sólidos voláteis incinerados a } 550^{\circ} \mathrm{C}-2540\end{array}$ \\
\hline $\begin{array}{l}\text { Alúminio, Cádmio, Cálcio, Chumbo, Cobalto, Cobre, } \\
\text { Cromo, Ferro, Fósforo, Magnésio, Manganês, Níquel, } \\
\text { Potássio, Silício, Sódio, Titânio, Zinco Totais }\left(\mathrm{mg}^{-1} \mathrm{~L}^{-1}\right)\end{array}$ & ICP-OES Plasma/ 3125 \\
\hline
\end{tabular}

\subsection{Classificação dos lodos de ETAs segundo a NBR 10.004 / 04}

A NBR 10.004 (2004) classifica os lodos provenientes do sistema de tratamento de água, bem como determinados líquidos cujas particularidades tornem inviável o seu lançamento na rede pública de esgoto ou corpos de água, ou exijam para isso soluções técnicas e economicamente inviáveis em face a melhor tecnologia disponível, como resíduos sólidos.

Segundo a NBR 10.004 (2004) a classificação dos resíduos sólidos envolve a identificação dos processos ou atividade que lhes deu origem e de seus constituintes e características, e a comparação destes constituintes com a listagens de resíduos e substancias cujo impacto à saúde e ao meio ambiente é conhecido.

Para classificação dos lodos tipos A e B, as amostras de lodos desidratadas com teor de sólidos na faixa de $80 \%$, foram enviadas a um laboratório credenciado e contratado para realizar os ensaios de lixiviação e solubilização, conforme estabelecido pela NBR 10.004 (2004).

Os ensaios de lixiviação e solubilização foram realizados de acordo com as NBRs 10.005 e 10.006 (ABNT, 2004), respectivamente. As análises dos parâmetros nos extratos 
lixiviados e solubilizados foram realizadas de acordo com as metodologias descritas em APHA, AWWA e WEF (2005).

Após o ensaio de lixiviação, para classificação do resíduo os resultados obtidos para cada parâmetro analisado foram comparados com os limites máximos nos extratos lixiviados estabelecidos no Anexo F da NBR 10.004 (2004).

A NBR 10.006 (ABNT, 2004) fixa os requisitos exigíveis para obtenção do extrato de solubilização de resíduos sólidos visando diferenciar os resíduos classificados na NBR 10.004 como classe II A - Não inertes - e classe II B - Inertes. Os resultados obtidos para cada parâmetro analisado foram comparados com os limites máximos no extrato solubilizado, estabelecidos no Anexo G da NBR 10.004 (2004).

\section{RESULTADOS}

\subsection{Ensaios de desaguamento em leitos de drenagem / secagem com manta geotêxtil}

Com objetivo de se obter um valor médio de teor de sólidos - ST, ao final do processo de desaguamento, foram realizados dois ensaios (desaguamento 1 e 2). Como mostra a Tabela 2, em tais condições de secagem, após 15 dias de desaguamento, sendo em média 2 dias de drenagem e 13 de secagem, os lodos tipos A e B desidratados apresentaram teor de sólidos na faixa de $80 \%$.

Tabela 2 - Resultados da secagem dos lodos tipos A e B

\begin{tabular}{|c|c|c|c|c|c|c|c|c|}
\cline { 2 - 8 } \multicolumn{1}{c|}{} & \multicolumn{4}{c|}{ Lodo Tipo A } & \multicolumn{4}{c|}{ Lodo Tipo B } \\
\cline { 2 - 9 } & $\begin{array}{c}\text { ST (\%) } \\
\text { após a } \\
\text { drenagem }\end{array}$ & $\begin{array}{c}\text { Tmédia } \\
\left({ }^{\circ} \mathrm{C}\right)\end{array}$ & $\begin{array}{c}\text { UR média } \\
(\%)\end{array}$ & $\begin{array}{c}\text { ST final } \\
(\%)\end{array}$ & $\begin{array}{c}\text { ST (\%) após } \\
\text { a drenagem }\end{array}$ & $\begin{array}{c}\text { Tmédia } \\
\left({ }^{\circ} \mathrm{C}\right)\end{array}$ & $\begin{array}{c}\text { UR média } \\
(\%)\end{array}$ & ST final $(\%)$ \\
\hline $\begin{array}{c}\text { Desaguamento } \\
1\end{array}$ & 15,3 & $28 \pm 3,6$ & $79,8 \pm 1,6$ & 86,1 & 14,1 & $28 \pm 3,6$ & $79,8 \pm 1,6$ & 86,8 \\
\hline $\begin{array}{c}\text { Desaguamento } \\
2\end{array}$ & 15,7 & $\begin{array}{c}25,9 \pm \\
3,6\end{array}$ & $75,9 \pm 12,8$ & 75,4 & 13,9 & $\begin{array}{c}25,9 \pm \\
3,6\end{array}$ & $75,9 \pm 12,8$ & 82,5 \\
\hline
\end{tabular}




\subsection{Ensaio em colunas de lixiviação}

A mistura dos lodos tipos A e B desitratados utilizados nas colunas de lixiviação apresentaram teor de sólidos de $77,8 \%$ e $79,5 \%$, respectivamente. Após a lixiviação foi observado um aumento de umidade da ordem de $4 \%$ dos lodos, ocasionada pela incorporação da água nos materiais sólidos. A Figura 3 mostra as amostras compostas dos líquidos lixiviados dos lodos tipos $\mathrm{A}$ e $\mathrm{B}$.

Figura 3 - Foto das amostras compostas dos líquidos lixiviados das colunas de lixiviação dos lodos tipos A e B

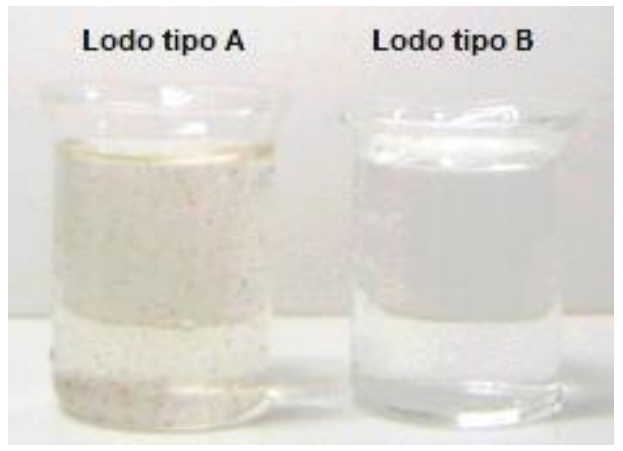

Na Tabela 2 é mostrada a caracterização físico, química e microbiológica das amostras compostas dos líquidos lixiviados dos lodos tipos A e B. 
Tabela 1 - Caracterização das amostras compostas dos lixiviados dos lodos tipos A e B

\begin{tabular}{|c|c|c|}
\hline Parâmetro & $\begin{array}{c}\text { Amostra composta do lixiviado - lodo } \\
\text { tipo A }\end{array}$ & $\begin{array}{l}\text { Amostra composta do lixiviado - } \\
\text { lodo tipo B }\end{array}$ \\
\hline $\mathrm{pH}$ & 5,5 & 5,1 \\
\hline Condutividade $\left(\mu \mathrm{S} . \mathrm{cm}^{-1}\right)$ & 44,5 & 39,7 \\
\hline Turbidez (uT) & 3,3 & 0,58 \\
\hline Coraparente $(\mathrm{uH})$ & 89 & 6,67 \\
\hline $\mathrm{DBO}\left(\mathrm{mg} \cdot \mathrm{L}^{-1}\right)$ & 2,9 & 2,9 \\
\hline DQO (mg. $\left.\mathrm{L}^{-1}\right)$ & 54,84 & 27,59 \\
\hline Alúminio Total $\left(\mathrm{mg} \mathrm{L}^{-1}\right)$ & 0,12 & 0,05 \\
\hline Ferro Total $\left(\mathrm{mg} \cdot \mathrm{L}^{-1}\right)$ & 0,10 & 0,007 \\
\hline Cádmio Total $\left(\mathrm{mg} \mathrm{L}^{-1}\right)$ & N.D & N.D \\
\hline Cálcio Total $\left(\mathrm{mg} \cdot \mathrm{L}^{-1}\right)$ & 3,45 & 2,82 \\
\hline Chumbo Total $\left(\mathrm{mg} \mathrm{L}^{-1}\right)$ & N.D & N.D \\
\hline Cobalto Total $\left(\mathrm{mg} \cdot \mathrm{L}^{-1}\right)$ & N.D & N.D \\
\hline Cobre Total $\left(\mathrm{mg} \cdot \mathrm{L}^{-1}\right)$ & 0,04 & 0,03 \\
\hline Cromo Total $\left(\mathrm{mg}^{-\mathrm{L}^{-1}}\right)$ & N.D & N.D \\
\hline Fósforo Total $\left(\mathrm{mg} \cdot \mathrm{L}^{-1}\right)$ & N.D & N.D \\
\hline Magnésio Total $\left(\mathrm{mg} \mathrm{L}^{-1}\right)$ & 1,01 & 0,27 \\
\hline Manganês Total (mg. $\left.\mathrm{L}^{-1}\right)$ & 0,44 & 0,67 \\
\hline Níquel Total $\left(\mathrm{mg} \cdot \mathrm{L}^{-1}\right)$ & N.D & N.D \\
\hline Potássio Total $\left(\mathrm{mg}^{\left.-\mathrm{L}^{-1}\right)}\right.$ & 0,30 & 0,30 \\
\hline Silício Total $\left(\mathrm{mg} \cdot \mathrm{L}^{-1}\right)$ & 5,42 & 1,07 \\
\hline Sódio Total $\left(\mathrm{mg} \cdot \mathrm{L}^{-1}\right)$ & 0,50 & 0,40 \\
\hline Titânio Total $\left(\mathrm{mg}^{\left.-\mathrm{L}^{-1}\right)}\right.$ & 0,007 & 0,003 \\
\hline Zinco Total $\left(\mathrm{mg}^{\circ} \mathrm{L}^{-1}\right)$ & $<L . Q$ & 0,02 \\
\hline
\end{tabular}

N.D - Não detectado

$<$ L.Q - Abaixo do limite de quantificação

O contato da água ultrapura com os lodos dispostos nas colunas de lixiviação provocou a alteração de alguns parâmetros, especialmente aumento da condutividade pela presença de sais nos lodos, DQO e alguns metais, em especial o cálcio e silício. Entretanto, esses valores não são considerados nocivos ao meio ambiente, pois apresentam-se abaixo dos limites estabelecidos pela Resolução 357/05 do Conama para enquadramento em corpos de água doce Classes I e II.

Segundo Ferranti (2006) a concentração de metais predomina de forma sensível na fase sólida do lodo. O ensaio de lixiviação revelou que os metais presentes na fase sólida do lodo muito provavelmente não oferecerão riscos ao meio ambiente, por não serem disponibilizados facilmente a partir do contato com a água, mesmo para a condição crítica de precipitação aplicada.

\subsection{Classificação dos lodos de ETA}


Nas Tabelas 4 a 7 são apresentados os resultados dos parâmetros analisados nos extratos lixiviados e solubilizados dos lodos tipos A e B.

Tabela 4 - Resultados dos parâmetros inorgânicos e orgânicos analisados nos extratos lixiviados do lodo

\begin{tabular}{|c|c|c|c|}
\hline Parâmetros & L.Q & $\begin{array}{l}\text { Limite NBR } 10.004 \\
\text { Anexo F }\end{array}$ & Resultados \\
\hline Arsênio $\left(m g \cdot L^{-1}\right)$ & 0,001 & 1 & $<$ L.Q \\
\hline Bário $\left(\mathrm{mg} \cdot \mathrm{L}^{-1}\right)$ & 0,07 & 70 & $<$ L.Q \\
\hline Cádmio $\left(\mathrm{mg} \cdot \mathrm{L}^{-1}\right)$ & 0,001 & 0,5 & $<$ L.Q \\
\hline Chumbo $\left(\mathrm{mg}^{-\mathrm{L}^{-1}}\right)$ & 0,01 & 1 & $<$ L.Q \\
\hline Cromo total $\left(\mathrm{mg} \mathrm{L}^{-1}\right)$ & 0,01 & 5 & $<$ L.Q \\
\hline Fluoreto $\left(\mathrm{mg} \cdot \mathrm{L}^{-1}\right)$ & 0,014 & 150 & $<$ L.Q \\
\hline Mercúrio $\left(\mathrm{mg} \cdot \mathrm{L}^{-1}\right)$ & 0,00006 & 0,1 & $<$ L.Q \\
\hline Prata $\left(m g . L^{-1}\right)$ & 0,01 & 5 & $<$ L.Q \\
\hline Selênio (mg. $\left.\mathrm{L}^{-1}\right)$ & 0,008 & 1 & $<$ L.Q \\
\hline Aldrin $\left(\mathrm{mg} \cdot \mathrm{L}^{-1}\right)$ & 0,005 & 0,003 & N.D \\
\hline Benzo(a)pireno $\left(\mathrm{mg} \mathrm{L}^{-1}\right)$ & 0,005 & 0,07 & N.D \\
\hline Cloreto de vinila $\left(\mathrm{mg}^{-\mathrm{L}^{-1}}\right)$ & 0,002 & 0,5 & N.D \\
\hline Clorobenzeno $\left(\mathrm{mg} \cdot \mathrm{L}^{-1}\right)$ & 0,002 & 100 & N.D \\
\hline Clorofórmio $\left(\mathrm{mg} \cdot \mathrm{L}^{-1}\right)$ & 0,002 & 6 & N.D \\
\hline m-Cresol $\left(\mathrm{mg}^{-\mathrm{L}^{-1}}\right)$ & 0,002 & 200 & N.D \\
\hline o-Cresol (mg. $\left.\mathrm{L}^{-1}\right)$ & 0,002 & 200 & N.D \\
\hline p-Cresol $\left(m g \cdot L^{-1}\right)$ & 0,002 & 200 & N.D \\
\hline $2,4-\mathrm{D}\left(\mathrm{mg} \cdot \mathrm{L}^{-1}\right)$ & 0,002 & 3 & N.D \\
\hline $\begin{array}{c}\text { DDT (p,p-DDT + p,p-DDE + p,p- } \\
\text { DDD) }\left(m g . L^{-1}\right)\end{array}$ & 0,005 & 0,2 & N.D \\
\hline 1,4-Diclorobenzeno $\left(\mathrm{mg} \mathrm{L}^{-1}\right)$ & 0,002 & 7,5 & N.D \\
\hline 1,2-Dicloroetano $\left(\mathrm{mg} \cdot \mathrm{L}^{-1}\right)$ & 0,002 & 1 & N.D \\
\hline 1,1-Dicloroetileno $\left(\mathrm{mg}^{-1} \mathrm{~L}^{-1}\right)$ & 0,002 & 3 & N.D \\
\hline 2 butanona $\left(\mathrm{mg} \mathrm{L}^{-1}\right)$ & 0,002 & 0,13 & N.D \\
\hline Endrin $\left(\mathrm{mg} \mathrm{L}^{-1}\right)$ & 0,005 & 0,06 & N.D \\
\hline Heptacloro hepóxido $\left(\mathrm{mg} \cdot \mathrm{L}^{-1}\right)$ & 0,005 & 0,003 & N.D \\
\hline Hexaclorobenzeno $\left(\mathrm{mg} \mathrm{L}^{-1}\right)$ & 0,005 & 0,1 & N.D \\
\hline Hexaclorobutadieno $\left(\mathrm{mg} \cdot \mathrm{L}^{-1}\right.$ ) & 0,002 & 0,5 & N.D \\
\hline Hexacloroetano $\left(\mathrm{mg} \cdot \mathrm{L}^{-1}\right)$ & 0,002 & 3 & N.D \\
\hline Metoxicloro $\left(\mathrm{mg} \cdot \mathrm{L}^{-1}\right)$ & 0,005 & 2 & N.D \\
\hline Nitrobenzeno $\left(\mathrm{mg}^{-\mathrm{L}^{-1}}\right)$ & 0,002 & 2 & N.D \\
\hline Pentaclorofenol $\left(\mathrm{mg}^{-\mathrm{L}^{-1}}\right)$ & 0,002 & 0,9 & N.D \\
\hline Piridina $\left(\mathrm{mg} \cdot \mathrm{L}^{-1}\right)$ & 2 & 5 & N.D \\
\hline $2,4,5-\mathrm{T}\left(\mathrm{mg} \cdot \mathrm{L}^{-1}\right)$ & 0,002 & 0,2 & N.D \\
\hline Tetracloreto de Carbono $\left(\mathrm{mg} \mathrm{L}^{-1}\right)$ & 0,002 & 0,2 & N.D \\
\hline Tetracloroetileno $\left(\mathrm{mg} \cdot \mathrm{L}^{-1}\right)$ & 0,002 & 4 & N.D \\
\hline Toxafeno $\left(\mathrm{mg} \mathrm{L}^{-1}\right)$ & 0,02 & 0,5 & N.D \\
\hline $2,4,5-\mathrm{TP}\left(\mathrm{mg} \cdot \mathrm{L}^{-1}\right)$ & 0,002 & 1 & N.D \\
\hline Tricloroetileno $\left(\mathrm{mg} \cdot \mathrm{L}^{-1}\right)$ & 0,002 & 7 & N.D \\
\hline $2,4,5-$ Triclorofenol $\left(\mathrm{mg}^{-\mathrm{L}^{-1}}\right)$ & 0,002 & 400 & N.D \\
\hline 2,4,6-Triclorofenol (mg. $\left.\mathrm{L}^{-1}\right)$ & 0,002 & 20 & N.D \\
\hline 2,4 - dinitrotolueno & 0,002 & 0,13 & N.D \\
\hline
\end{tabular}


< L.Q - abaixo do limite de quantificação

Tabela 5 - Resultados dos parâmetros inorgânicos e orgânicos analisados nos extratos solubilizados do lodo tipo A

\begin{tabular}{|c|c|c|c|}
\hline Parâmetros & L.Q & $\begin{array}{c}\text { Limite NBR } 10.004 \\
\text { Anexo G }\end{array}$ & Resultados \\
\hline Alumínio $\left(\mathrm{mg} \cdot \mathrm{L}^{-1}\right)$ & 0,1 & 0,2 & $<$ L.Q \\
\hline Arsênio (mg. $\left.\mathrm{L}^{-1}\right)$ & 0,001 & 0,01 & $<$ L.Q \\
\hline Bário $\left(\mathrm{mg} \cdot \mathrm{L}^{-1}\right)$ & 0,07 & 0,7 & $<$ L.Q \\
\hline Cádmio $\left(\mathrm{mg}^{-\mathrm{L}^{-1}}\right)$ & 0,001 & 0,005 & $<$ L.Q \\
\hline Chumbo (mg. $\left.\mathrm{L}^{-1}\right)$ & 0,01 & 0,01 & $<$ L.Q \\
\hline Cianetos (mg. $\left.\mathrm{L}^{-1}\right)$ & 0,002 & 0,07 & $<$ L.Q \\
\hline Cloretos (mg. $\left.\mathrm{L}^{-1}\right)$ & 2,5 & 250 & 84.23 \\
\hline Cromo total $\left(\mathrm{mg} \cdot \mathrm{L}^{-1}\right)$ & 0,01 & 0,3 & $<$ L.Q \\
\hline Cobre $\left(\mathrm{mg} \cdot \mathrm{L}^{-1}\right)$ & 0,009 & 2 & $<$ L.Q \\
\hline Ferro $\left(m g \cdot \mathrm{L}^{-1}\right)$ & 0,03 & 0,3 & 3,97 \\
\hline Fluoreto $\left(\mathrm{mg}^{\left.-\mathrm{L}^{-1}\right)}\right.$ & 0,14 & 1,5 & $<$ L.Q \\
\hline Manganês $\left(\mathrm{mg} \mathrm{L}^{-1}\right)$ & 0,01 & 0,1 & 9,47 \\
\hline Mercúrio $\left(\mathrm{mg} \cdot \mathrm{L}^{-1}\right)$ & 0,00006 & 0,001 & $<$ L.Q \\
\hline Nitrato $\left(\mathrm{mg} \cdot \mathrm{L}^{-1}\right)$ & 0,1 & 10 & 8,4 \\
\hline Prata $\left(\mathrm{mg} \cdot \mathrm{L}^{-1}\right)$ & 0,01 & 0,05 & $<$ L.Q \\
\hline Selênio $\left(\mathrm{mg} \cdot \mathrm{L}^{-1}\right)$ & 0,008 & 0,01 & $<$ L.Q \\
\hline Sódio $\left(\mathrm{mg} \cdot \mathrm{L}^{-1}\right)$ & 0,1 & 200 & 4,9 \\
\hline Sulfato $\left(\mathrm{mg} \cdot \mathrm{L}^{-1}\right)$ & 25 & 250 & 83,8 \\
\hline Surfactantes $\left(\mathrm{mg} \cdot \mathrm{L}^{-1}\right)$ & 0,05 & 0,5 & 0,09 \\
\hline Zinco $\left(m g . \mathrm{L}^{-1}\right)$ & 0,1 & 5 & $<$ L.Q \\
\hline Aldrin e Dieldrin (mg. $\left.\mathrm{L}^{-1}\right)$ & 0,00003 & $3 \times 10^{-5}$ & N.D \\
\hline Clordano $\left(\mathrm{mg} \mathrm{L}^{-1}\right)$ & 0,00003 & $2 \times 10^{-4}$ & N.D \\
\hline $2,4-\mathrm{D}\left(\mathrm{mg} \cdot \mathrm{L}^{-1}\right)$ & 0,001 & 0,03 & N.D \\
\hline DDT 2,4-D (mg.t.-1) & 0,00003 & $2 \times 10^{-3}$ & N.D \\
\hline Endrin & 0,00003 & $6 \times 10^{-4}$ & N.D \\
\hline Fenóis totais & 0,002 & 0,01 & N.D \\
\hline Hepctacloro hepóxido $\left(\mathrm{mg} \cdot \mathrm{L}^{-1}\right)$ & 0,00003 & $3 \times 10^{-5}$ & N.D \\
\hline Hexaclorobenzeno $\left(\mathrm{mg} \mathrm{L}^{-1}\right)$ & 0,00003 & $1 \times 10^{-3}$ & N.D \\
\hline Metoxicloro $\left(\mathrm{mg} \cdot \mathrm{L}^{-1}\right)$ & 0,00003 & 0,02 & N.D \\
\hline $2,4,5-\mathrm{T}\left(\mathrm{mg} \cdot \mathrm{L}^{-1}\right)$ & 0,001 & $2 \times 10^{-3}$ & N.D \\
\hline Toxafeno $\left(\mathrm{mg} \cdot \mathrm{L}^{-1}\right)$ & 0,002 & $5 \times 10^{-3}$ & N.D \\
\hline 2,4,5-TP $\left(\mathrm{mg} \cdot \mathrm{L}^{-1}\right)$ & 0,001 & 0,03 & N.D \\
\hline
\end{tabular}

ND - não detectado

$<$ L.Q - abaixo do limite de quantificação

O ensaio de lixiviação do lodo tipo A teve duração de 18 horas, tendo sido coletado $1,72 \mathrm{~L}$ de extrato lixiviado. Os extratos lixiviado e solubilizado apresentaram $\mathrm{pH}$ da ordem de 5 . $O$ teor de umidade do extrato solubilizado foi de $3,89 \%$. Analisando as Tabelas 4 e 5 , em relação as análises do lodo tipo $A$ foram obtidos os seguintes 
resultados:

- Lixiviado: os parâmetros analisados no extrato lixiviado apresentaram concentrações adequadas às indicadas no Anexo F da NBR 10.004 (2004);

- Solubilizado: com exceção dos parâmetros ferro e manganês totais, os parâmetros analisados apresentaram concentrações adequadas às indicadas no Anexo $G$ da NBR 10.004 (2004).

Tabela 6 - Resultados dos parâmetros inorgânicos e orgânicos analisados nos extratos lixiviados do lodo tipo B 


\begin{tabular}{|c|c|c|c|}
\hline Parâmetros & L.Q & $\begin{array}{l}\text { Limite NBR } 10.004- \\
\text { Anexo F }\end{array}$ & Resultados \\
\hline Arsênio $\left(\mathrm{mg} \cdot \mathrm{L}^{-1}\right)$ & 0,04 & 1 & $<\mathrm{L} . \mathrm{Q}$ \\
\hline Bário $\left(\mathrm{mg} \cdot \mathrm{L}^{-1}\right)$ & 0,005 & 70 & 0,37 \\
\hline Cádmio (mg. $\left.\mathrm{L}^{-1}\right)$ & 0,003 & 0,5 & $<$ L.Q \\
\hline Chumbo (mg. $\left.\mathrm{L}^{-1}\right)$ & 0,03 & 1 & $<$ L.Q \\
\hline Cromo total $\left(\mathrm{mg} \cdot \mathrm{L}^{-1}\right)$ & 0,002 & 5 & 0,003 \\
\hline Fluoreto $\left(\mathrm{mg}^{-\mathrm{L}^{-1}}\right)$ & 0,05 & 150 & $<0,05$ \\
\hline Mercúrio (mg. $\left.\mathrm{L}^{-1}\right)$ & 0,0005 & 0,1 & $<$ L.Q \\
\hline Prata $\left(m g \cdot L^{-1}\right)$ & 0,003 & 5 & $<$ L.Q \\
\hline Selênio $\left(m g \cdot L^{-1}\right)$ & 0,05 & 1 & $<$ L.Q \\
\hline Aldrin e Dieldrin $\left(\mathrm{mg} \mathrm{L}^{-1}\right)$ & 0,001 & 0,003 & $<$ L.Q \\
\hline Benzeno (mg. $\left.\mathrm{L}^{-1}\right)$ & 0,004 & 0,5 & $<$ L.Q \\
\hline Benzo(a)pireno $\left(\mathrm{mg} \mathrm{L}^{-1}\right)$ & 0,002 & 0,07 & $<$ L.Q \\
\hline Clordano (isômeros) $\left(\mathrm{mg} \mathrm{L}^{-1}\right)$ & 0,001 & 0,02 & $<$ L.Q \\
\hline Cloreto de vinila $\left(\mathrm{mg} \mathrm{L}^{-1}\right)$ & 0,4 & 0,5 & $<$ L.Q \\
\hline Clorobenzeno $\left(\mathrm{mg} \cdot \mathrm{L}^{-1}\right)$ & 0,01 & 100 & $<$ L.Q \\
\hline Clorofórmio $\left(\mathrm{mg} \mathrm{L}^{-1}\right)$ & 0,004 & 6 & $<$ L.Q \\
\hline m-Cresol (mg. $\left.\mathrm{L}^{-1}\right)$ & 0,01 & 200 & $<$ L.Q \\
\hline o-Cresol (mg. $\left.\mathrm{L}^{-1}\right)$ & 0,01 & 200 & $<$ L.Q \\
\hline p-Cresol (mg. L $\left.^{-1}\right)$ & 0,01 & 200 & $<$ L.Q \\
\hline Cresol Total $\left(\mathrm{mg} \mathrm{L}^{-1}\right)$ & 0,01 & 200 & $<$ L.Q \\
\hline $2,4-\mathrm{D}\left(\mathrm{mg} \cdot \mathrm{L}^{-1}\right)$ & 0,01 & 3 & $<$ L.Q \\
\hline $\begin{array}{c}\text { DDT (p,p-DDT + p,p-DDE + p,p- } \\
\text { DDD) }\left(m g . L^{-1}\right)\end{array}$ & 0,001 & 0,2 & $<$ L.Q \\
\hline 1,4-Diclorobenzeno $\left(\mathrm{mg} \mathrm{L}^{-1}\right)$ & 0,004 & 7,5 & $<$ L.Q \\
\hline 1,2-Dicloroetano (mg. $\mathrm{L}^{-1}$ ) & 0,004 & 1 & $<$ L.Q \\
\hline 1,1-Dicloroetileno $\left(\mathrm{mg}^{-1} \mathrm{~L}^{-1}\right)$ & 0,004 & 3 & $<$ L.Q \\
\hline 2,4-Dinitrotolueno $\left(\mathrm{mg}^{-1} \mathrm{~L}^{-1}\right)$ & 0,01 & 0,13 & $<$ L.Q \\
\hline Endrin $\left(\mathrm{mg} \mathrm{L}^{-1}\right)$ & 0,001 & 0,06 & $<$ L.Q \\
\hline Heptacloro e seu epóxido $\left(\mathrm{mg} \cdot \mathrm{L}^{-1}\right)$ & 0,001 & 0,003 & $<$ L.Q \\
\hline Hexaclorobenzeno $\left(\mathrm{mg}^{-\mathrm{L}^{-1}}\right)$ & 0,001 & 0,1 & $<$ L.Q \\
\hline Hexaclorobutadieno $\left(\mathrm{mg} \mathrm{L}^{-1}\right)$ & 0,004 & 0,5 & $<$ L.Q \\
\hline Hexacloroetano (mg. $\mathrm{L}^{-1}$ ) & 0,01 & 3 & $<$ L.Q \\
\hline Lindano $(\mathrm{g} \mathrm{BHC})\left(\mathrm{mg} \cdot \mathrm{L}^{-1}\right)$ & 0,5 & 0,2 & $<$ L.Q \\
\hline Metiletilcetona $\left(\mathrm{mg} \cdot \mathrm{L}^{-1}\right)$ & 0,001 & 200 & $<$ L.Q \\
\hline Metoxicloro $\left(\mathrm{mg} \cdot \mathrm{L}^{-1}\right)$ & 0,01 & 2 & $<$ L.Q \\
\hline Nitrobenzeno $\left(\mathrm{mg} \mathrm{L}^{-1}\right)$ & 0,01 & 2 & $<$ L.Q \\
\hline Pentaclorofenol $\left(\mathrm{mg} \cdot \mathrm{L}^{-1}\right)$ & 0,01 & 0,9 & $<$ L.Q \\
\hline Piridina $\left(\mathrm{mg} \cdot \mathrm{L}^{-1}\right)$ & 0,002 & 5 & $<$ L.Q \\
\hline $2,4,5-\mathrm{T}\left(\mathrm{mg} \cdot \mathrm{L}^{-1}\right)$ & 0,004 & 0,2 & $<$ L.Q \\
\hline Tetracloreto de Carbono $\left(\mathrm{mg} \mathrm{L}^{-1}\right)$ & 0,004 & 0,2 & $<$ L.Q \\
\hline Tetracloroetileno $\left(\mathrm{mg} \mathrm{L}^{-1}\right)$ & 0,004 & 4 & $<$ L.Q \\
\hline Toxafeno $\left(\mathrm{mg} \mathrm{L}^{-1}\right)$ & 0,002 & 0,5 & $<$ L.Q \\
\hline $2,4,5-\mathrm{TP}\left(\mathrm{mg} \cdot \mathrm{L}^{-1}\right)$ & 0,01 & 1 & $<$ L.Q \\
\hline Tricloroetileno $\left(\mathrm{mg} . \mathrm{L}^{-1}\right)$ & 0,004 & 7 & $<$ L.Q \\
\hline 2,4,5-Triclorofenol $\left(\mathrm{mg}^{\left.-\mathrm{L}^{-1}\right)}\right.$ & 0,01 & 400 & $<$ L.Q \\
\hline 2,4,6-Triclorofenol $\left(\mathrm{mg}^{-\mathrm{L}^{-1}}\right)$ & 0,01 & 20 & $<$ L.Q \\
\hline
\end{tabular}

ND - não detectado

$<$ L.Q - abaixo do limite de quantificação 
Tabela 7 - Resultados dos parâmetros inorgânicos e orgânicos analisados nos extratos solubilizados do lodo tipo B

\begin{tabular}{|c|c|c|c|}
\hline Parâmetros & L.Q & $\begin{array}{c}\text { Limite NBR } 10.004- \\
\text { Anexo G }\end{array}$ & Resultados \\
\hline Alumínio $\left(\mathrm{mg} \cdot \mathrm{L}^{-1}\right)$ & 0,05 & 0,2 & $<$ L.Q \\
\hline Arsênio $\left(m g \cdot \mathrm{L}^{-1}\right)$ & 0,001 & 0,01 & $<$ L.Q \\
\hline Bário $\left(m g . \mathrm{L}^{-1}\right)$ & 0,005 & 0,7 & 0,38 \\
\hline Cádmio $\left(\mathrm{mg} \cdot \mathrm{L}^{-1}\right)$ & 0,003 & 0,005 & $<, L . Q$ \\
\hline Chumbo (mg. $\left.\mathrm{L}^{-1}\right)$ & 0,002 & 0,01 & $<$ L.Q \\
\hline Cianetos $\left(\mathrm{mg} \cdot \mathrm{L}^{-1}\right)$ & 0,005 & 0,07 & 0,0058 \\
\hline Cloretos $\left(\mathrm{mg}_{\mathrm{L}} \mathrm{L}^{-1}\right)$ & 0,01 & 250 & 150 \\
\hline Cromo total $\left(\mathrm{mg} \mathrm{L}^{-1}\right)$ & 0,002 & 0,3 & $<$ L.Q \\
\hline Cobre $\left(\mathrm{mg} . \mathrm{L}^{-1}\right)$ & 0,003 & 2 & $<$ L.Q \\
\hline Ferro $\left(m g . L^{-1}\right)$ & 0,002 & 0,3 & $<$ L.Q \\
\hline Fluoreto $\left(\mathrm{mg}^{-\mathrm{L}^{-1}}\right)$ & 0,05 & 1,5 & 0,059 \\
\hline Manganês $\left(\mathrm{mg} \cdot \mathrm{L}^{-1}\right)$ & 0,002 & 0,1 & 2,15 \\
\hline Mercúrio $\left(\mathrm{mg}_{\mathrm{L}} \mathrm{L}^{-1}\right)$ & 0,0005 & 0,001 & $<$ L.Q \\
\hline Nitrato $\left(\mathrm{mg} \mathrm{L}^{-1}\right)$ & 0,1 & 10 & 0,19 \\
\hline Prata $\left(m g \cdot L^{-1}\right)$ & 0,003 & 0,05 & $<$ L.Q \\
\hline Selênio $\left(m g \cdot L^{-1}\right)$ & 0,002 & 0,01 & $<$ L.Q \\
\hline Sódio $\left(\mathrm{mg} \cdot \mathrm{L}^{-1}\right)$ & 0,05 & 200 & 3,97 \\
\hline Sulfato $\left(m g \cdot L^{-1}\right)$ & 1 & 250 & 16,6 \\
\hline Surfactantes $\left(\mathrm{mg}^{\left.-\mathrm{L}^{-1}\right)}\right.$ & 0,03 & 0,5 & $<0,03$ \\
\hline Zinco $\left(\mathrm{mg}^{\mathrm{L}} \mathrm{L}^{-1}\right)$ & 0,006 & 5 & 0,04 \\
\hline Aldrin e Dieldrin (mg. $\left.\mathrm{L}^{-1}\right)$ & $2 \times 10^{-5}$ & $3 \times 10^{-5}$ & $<$ L.Q \\
\hline Clordano $\left(\mathrm{mg} \mathrm{L}^{-1}\right)$ & 0,0002 & $2 \times 10^{-4}$ & $<$ L.Q \\
\hline $2,4-\mathrm{D}\left(\mathrm{mq} \cdot \mathrm{L}^{-1}\right)$ & 0,01 & 0,03 & $<$ L.Q \\
\hline DDT 2,4-D (mg. $\left.\mathrm{L}^{-1}\right)$ & 0,001 & $2 \times 10^{-3}$ & $<$ L.Q \\
\hline Endrin & 0,0002 & $6 \times 10^{-4}$ & $<$ L.Q \\
\hline Fenóis totais & 0,0011 & 0,01 & 0,035 \\
\hline Hepctacloro e seu epóxido $\left(\mathrm{mg} \mathrm{L}^{-1}\right)$ & $2 \times 10^{-5}$ & $3 \times 10^{-5}$ & $<$ L.Q \\
\hline Hexaclorobenzeno $\left(\mathrm{mg} \mathrm{L}^{-1}\right)$ & 0,001 & $1 \times 10^{-3}$ & $<$ L.Q \\
\hline Lindano $(\mathrm{g} \mathrm{BHC})\left(\mathrm{mg}^{-\mathrm{L}^{-1}}\right)$ & 0,001 & $2 \times 10^{-3}$ & $<$ L.Q \\
\hline Metoxicloro $\left(\mathrm{mg}^{-\mathrm{L}^{-1}}\right)$ & 0,001 & 0,02 & $<$ L.Q \\
\hline $2,4,5-\mathrm{T}\left(\mathrm{mg} \cdot \mathrm{L}^{-1}\right)$ & 0,002 & $2 \times 10^{-3}$ & $<$ L.Q \\
\hline Toxafeno $\left(\mathrm{mg}^{-1} \mathrm{~L}^{-1}\right)$ & 0.002 & $5 \times 10^{-3}$ & $<$ L.Q \\
\hline $2,4,5-\mathrm{TP}\left(\mathrm{mg}^{-\mathrm{L}^{-1}}\right)$ & 0,01 & 0,03 & $<$ L.Q \\
\hline
\end{tabular}

$\mathrm{ND}$ - não detectado

$<$ L.Q - abaixo do limite de quantificação

O ensaio de lixiviação do lodo tipo $B$ teve duração de 18 horas, tendo sido coletado $2 \mathrm{~L}$ de extrato lixiviado. Os extratos lixiviado e solubilizado apresentaram $\mathrm{pH}$ na ordem de 5. O extrato solubilizado apresentou teor de umidade de $12 \%$.

Em relação as análises do lodo tipo B (Tabela 6 e Tabela 7) foram obtidos os seguintes resultados: 
- Lixiviado: os parâmetros analisados no lixiviado apresentaram concentrações adequadas às indicadas no Anexo F da NBR 10.004 (2004);

- Solubilizado: com exceção do parâmetros manganês e fenóis totais, os parâmetros analisados apresentaram concentrações adequadas às indicadas no Anexo G da NBR 10.004 (2004).

Por apresentar constituintes que são solubilizados em concentrações superiores aos limites estabelecidos no Anexo G da NBR 10.004 (2004), os lodos tipos A e B foram classificados como resíduo Classe II A - Não inertes.

\section{CONCLUSÕES}

O ensaio em colunas de lixiviação revelou que em relação aos aspectos analisados nesse estudo, os lodos de ETAs desidratados podem ser dispostos como cobertura de células em aterro sanitário, uma vez que os metais presentes não foram disponibilizados quando em contato com a água, mesmo para a condição crítica de precipitação aplicada, e, portanto, muito provavelmente não oferecerão riscos ao meio ambiente.

Em relação à classificação dos lodos de ETAs segundo a NBR 10.004 (2004), os lodos tipos A e B foram classificados como resíduo Classe II A - Não inertes por apresentar constituintes que foram solubilizados em concentrações superiores aos limites estabelecidos no Anexo G da NBR 10.004 (2004).

\section{REFERÊNCIAS}

APHA, AWWA, WEF, Standard Methods For The Examination Of Water \& Wastewater 21st Edition, 2005.

RODRIGUEZ, T. T.; TEIXEIRA, R. S. FERNANDES, F. OLIVEIRA JUNIOR, O. M.; MARTINS, F. B.; DANZIGER, F. A. B. Estudo da compactação de lodo de ETA para 
uso em aterros sanitários. In: VII Congresso Brasileiro de Geotecnia Ambiental REGEO, Belo Horizonte, 2011. 